http://dx.doi.org/10.12795/PH.1990.v05.i01.25

\title{
Escritura e ideología en la narrativa antiesclavista cubana
}

Mercedes Rivas

Hacia 1838 el género novelesco hace su aparición en la Isla de Cuba; sus primeras manifestaciones en forma de relatos de ficción o costumbristas surgían con la llegada del nuevo siglo. Las crónicas habaneras de «El Regañón», las narraciones de tono fantástico del primer Cirilo Villaverde -La Peña Blanca y La Cueva de Taganana (1837)-, o el indianismo de Ramón de Palma en Matanzas y Yumurí (1837) constituyen el germen de la novela cubana primitiva ${ }^{1}$.

Son dos obras de este último autor las que encabezan la historia del género: Una Pascua en San Marcos y El cólera en La Habana fueron publicadas en $1838^{2}$. Aunque «dominado totalmente por el romanticismo idealizador», al decir de Salvador Bueno ${ }^{3}$, y con los titubeos propios de toda literatura en vías de gestación, Ramón de Palma compone dos novelas de estructura narrativa simple y trama folletinesca, pero ya se adivina en ellas una inquietud por los males que afectaban a la sociedad cubana de su tiempo. Pronto se advirtió este cariz social entre sus contemporáneos:

«Esto no es la Peña Blanca de Villaverde, en que se campea de vez en cuando una naturalidad de tono, sumamente original y cubano, también hay mucho de vaporoso y de fantástico. /.../-Echevarría me escribe que se decía que es inmoral y que pensaba hacer juicio crítico de ella-. Inmoral! En qué es inmoral esa obrita? En revelar nuestras

${ }^{1}$ Villaverde, Cirilo, «La Peña Blanca» y «La Cueva de Taganana», en Homenaje a Cirilo Villaverde. Cuba en La Unesco, marz. 1964, años 3-4-5, n.5 (La Habana: Comisión Nacional Cubana de la Unesco, 1964), pp. 254-268 y 276-306; y Palma, Ramón de, «Matanzas y Yumurí, en Cuentos Cubanos (La Habana: Cultural S.A., 1928), pp. 3-20.

2 Palma, Ramón de, op., cit., pp. 21-102 y pp. 103-168.

${ }^{3}$ Bueno, Salvador, «Prólogo», en Cuentos Cubanos del siglo XIX (La Habana: Arte y Literatura, 1975), p. 25. 
costumbres? En pintar tales cuales nuestros libertinos, idiotas y viciosos? En retratar nuestras novelescas muchachas, cuya inocencia peligrosa se nutre de lecturas caballerescas, y luego quiere buscar los tipos europeos en nuestra sociedad llena de corrupción y de barbarie?»

Así defendía el malogrado poeta cubano José Jacinto Milanés la novela Una Pascua en San Marcos en carta a Domingo del Monte, mentor de toda esta generación de escritores e intelectuales cubanos. De esta forma, a pesar de estar imbuida de caracteres románticos, la primitiva narración cubana registra las circunstancias que en aquellos momentos vivía la aún colonia española, y lo hacía con un estilo afín al realismo balzaciano, autor muy admirado y comentado por este grupo de autores cubanos. Este implicarse con la historia de su país nunca será lo suficientemente resaltado, pues el ropaje sentimentalista de las novelas de Palma y de las otras muchas que le sucedieron ha difuminado el trazo más auténtico de esta literatura.

Sin embargo, no todos los contemporáneos de Palma se identificaron con su forma de novelar, ya que había eliminado de sus composiciones un aspecto capital en el universo isleño: la esclavitud y la figura del negro. Tal es el parecer de Félix Tanco y Bosmeniel, cubano de adopción y miembro destacado de la tertulia delmontina; Tanco comentaba a Del Monte este aspecto en una de las numerosas cartas que dirigió al intelectual dominicano:

«Los jóvenes que hoy están escribiendo novelas creo que no lo aciertan en describir amoríos o galanteos en los de su clase o color, en describir la propia corrupción de esta clase, sin acordarse absolutamente de los esclavos, que tan poderosa parte tienen en esta corrupción; apenas se atreven a escribir la palabra bocabajo, las palabras mal pronunciadas o la algarabía de los negros bozales, con lo cual creen que han pintado el país. La novela de Palma, que es la que tiene más colorido cubano, adolece sin embargo del defecto que he dicho. Un negro viejo, un taita brujo, es todo lo que se ve como de paso en toda la relación; personaje ridículo, cuando los esclavos no lo son, y personaje singular que no parece sino que es el único que existe en el país, o en San Marcos, donde gracias a Dios hay algunos más» ${ }^{5}$.

Encomendaba Tanco al escritor cubano la tarea de mostrar cada una de las capas que componían su sociedad, y, sobre todo, creía necesario retratar las vivencias de los negros en Cuba, pues sólo mediante una pintura fiel de este estrato sojuzgado y en la expresión de la verdadera naturaleza de sus relaciones con el esclavista blanco podrían encontrar los cubanos una solución para su pueblo. La escritura era para Tanco un medio

${ }^{4}$ Del Monte, Domingo, Centón Epistolario de Domingo del Monte (La Habana: Imprenta Siglo XX, 1923-1938), III, p. 158. El amigo Echevarría nombrado en el texto es José Antonio Echevarría, autor de la primera novela histórica cubana, Antonelli (1839) -se ha modernizado la ortografía en todas las citas del Centón-.

${ }^{5}$ Ibidem, VII, p. 114. Todas las cartas que Tanco dirigiera a Del Monte desde 1823 se agrupan en este volumen del Centón, documento de un valor inapreciable para comprender los diversos avatares que asolaron a los jóvenes delmontinos, tanto intelectualmente como personal o políticamente. 
de luchar abiertamente contra la esclavitud, la razón más culpable del atraso y la dejadez moral de la colonia, y objeto evidente de la crueldad -mental y física- de una minoría dominada por un afán desmedido de riquezas:

«Dejemos la ridícula manía o el error de pintar una sociedad escogida, la sociedad blanca sola, aislada, porque los negros se destinen y ensucian a esa sociedad, y es preciso verla con los tiznes que le deja su roce: es decir, que es necesario, imprescindible, ver los negritos» ${ }^{6}$.

De todas formas, más allá de la insistencia de Tanco en el tema del negro es importante destacar cómo desde las tempranas fechas de su nacimiento la novela cubana mostraba un profundo interés por desvelar el marco extraliterario en el cual se originaba y revelarlo en toda su magnitud al público lector. No es la cubana, por tanto, una literatura neutral ante su historia, y en este compromiso con ella reside una de sus características fundamentales.

\section{Novela y compromiso social}

La iniciativa de Domingo del Monte inducía a los amigos de su tertulia a interesarse de un modo alarmante por la sociedad de su país, y al mismo tiempo intentaba enlazar este hecho al desarrollo de una literatura plenamente cubana. No es de extrañar, por tanto, que pronto sociedad y literatura quedasen vinculadas dentro del círculo delmontino, ni que, justamente por ello, la literatura se contemplara como un vehículo de denuncia social. Del Monte y sus contertulios - Tanco, Milanés, Suárez y Romero, entre otros- ayudarían a forjar la identidad cubana y, como cita Luis Yero Pérez, prepararon el terreno «para la consolidación de una tradición narrativa realista, preocupada por los asuntos locales, /.../ (que) constituyó la clave del lento y complejo proceso descolonizador»?

Convencer de que el régimen esclavista violaba los derechos naturales del ser humano y limitaba el progreso de la sociedad fue la primera consigna de los novelistas que comenzaban a escribir a raíz del magisterio de Del Monte, y los relatos de estos primeros narradores cubanos constituirían la base de la narración antiesclavista en Cuba, que más tarde afirmarán otros títulos significativos escritos a lo largo del siglo. Los autores y obras que encabezan este metagénero los recogemos ahora: Félix Tanco con Petrona y Rosalía (1838/1925), Juan Francisco Manzano con la Autobiografía de un esclavo (1838/1840), El Ranchador (1838/1856) de Pedro José Morillas, Anselmo Súarez y Romero con Francisco. El ingenio o las delicias del campo (1839/1880), Sab (1841) de Gertrudis Gómez de Avellaneda, Antonio Zambrana con El negro

\footnotetext{
6 Ibidem, VII, p. 120.

${ }^{7}$ Yero Pérez, Luis, «El tema de la esclavitud en la narrativa cubana», Islas, n. 49 (sept.-dic. 1974), p.
} 70. 
Francisco (1873) y Cecilia Valdés o La Loma del Angel (1879/1882) de Cirilo Villaverde ${ }^{8}$.

De todos estos escritores, sólo Gertrudis Gómez de Avellaneda y Antonio Zambrana no conocieron directamente la intelectualidad delmontina por diversas razones: la escritora cubana se traslada a España en 1836, dos años antes de que salieran a la luz los primeros frutos del círculo, y Zambrana nacía dos décadas después, en 1846.

Pero aunque no vivieron esa efervescencia cultural, participaron de ella en otro sentido. El carácter inquieto y curioso de la Avellaneda desde su juventud hizo que su residencia familiar se erigiera en punto de encuentro para las personalidades más cultivadas de su Camagüey natal; «a su alrededor», comenta su biógrafa Mercedes Ballesteros, «se formó una escogida sociedad de aficionados a las letras, y las veladas de su casa fueron el centro de reunión de lo más selecto de la ciudad. Se recitaban versos de Corneille y Racine, de Quintana, Gallego, Meléndez Valdés y del gran poeta cubano Heredia, famoso cantor del Niágara, cuya influencia en la gran poetisa es tan patente»9.

Por otra parte, el aislamiento característico de la región camagüeyana alentó en la zona un fuerte espíritu autonomista. En Puerto Príncipe se sostuvo durante todo el siglo una gran actividad revolucionaria, e incluso abolicionista; incansable fue la lucha por la autonomía de Gaspar Betancourt Cisneros, conocido como escritor costumbrista por el sobrenombre de «El Lugareño» y famoso activista político que se había trasladado a la zona en los años previos al primer viaje a España de la Avellaneda; también vivía en la región el abolicionista Joaquín de Agüero, el cual libertó a sus esclavos y fue ajusticiado por participar en los alzamientos del independentista Narciso López a mediados del siglo.

En lo relativo a Antonio Zambrana, su carrera fue posterior a estos años de gestación literaria, pero también se sumaría al mundillo cultural de la segunda mitad del XIX. Zambrana asistía regularmente a las tertulias convocadas por su tío Ramón Zambrana y su esposa, la poetisa Luisa Pérez, la cual recrea en carta a Suárez y Romero la lectura de unos «Fragmentos» de Francisco, obra sólo conocida en los ambientes literarios por haber sido prohibida su publicación en la isla debido a su credo antiesclavista:

\footnotetext{
${ }^{8}$ Los autores y relatos antiesclavistas recogidos en este artículo son lo siguientes (las citas que aparezcan corresponderán a estas ediciones):

Gómez de Avellaneda, Gertrudis, Sab (La Habana: Arte y Literatura, 1976).

Manzano, Juan Francisco, Autobiografía de un esclavo (Madrid: Guadarrama, 1975).

Morillas, Pedro José, «El Ranchador», en Noveletas cubanas (La Habana: Arte y Literatura, 1977).

Suárez y Romero, Anselmo, Francisco. El ingenio o las delicias del campo (La Habana: Publicaciones del Ministerio de Educación, Dirección de Cultura, 1947).

Tanco y Bosmeniel, Félix, «Petrona y Rosalía», en Cuentos Cubanos del siglo XIX (La Habana: Arte y Literatura, 1975).

Villaverde, Cirilo, Cecilia Valdés o La Loma del Angel (Caracas: Biblioteca Ayacucho, 1981).

Zambrana, Antonio, El negro Francisco (La Habana: Imprenta Fernández y Cía., 1953).

${ }^{9}$ Ballesteros, Mercedes, Vida de la Avellaneda (Madrid: Cultura Hispánica, 1949), p. 16.
} 
«Recuerdo perfectamente la deliciosa noche de invierno de 1865, en que accediendo usted a las repetidas instancias de mi inolvidable esposo, a las mías y a las de toda mi familia, tuvo bondad de leernos los sublimes y poéticos fragmentos de su novela Francisco /.... Ni una sola reflexión de su parte, ni una sola queja, ni una sola palabra sobre las injusticias, las pasiones y los errores del hombre; y no obstante ¡cómo defiende usted, sin parecer pretenderlo, la causa de la justicia y de la verdad! ¡Cómo defiende usted los derechos de la sociedad ultrajada! ¡Cómo presta usted admirables gemidos al sufrimiento sin protección! Y todo esto ¡con qué desgarradora elocuencia!» ${ }^{10}$.

No es de extrañar que la lectura de estos fragmentos inspirara a Antonio Zambrana para recrear el relato de Suárez y Romero en su novela El negro Francisco. Por otra parte, gracias a estos datos podemos comprobar la permanencia de un espíritu similar al delmontino entre ciertos ambientes y en un período muy próximo a la primera gesta revolucionaria cubana.

De tal modo, y a lo largo de más de cuarenta años, diversos escritores cubanos elegirían un tipo de literatura combativo que se hiciera eco y denunciara a un tiempo la barbarie esclavista, ese «mal necesario» para algunos -los dueños poseedores de la tierra, para los que el esclavo era la única fuerza productiva-, y que sólo una minoría tratará de desarraigar de la isla.

\section{Narrativa antiesclavista}

El conjunto de relatos indicado anteriormente elabora su argumento en función de un conflicto determinado por una marca biológica del protagonista: el color de su piel, ya sea blanco, negro o cobrizo. Este conflicto se origina en un personaje en lucha con su entorno y su autenticidad reside propiamente en alcanzar la trascendencia sociohistórica que en un principio se planteaba como un hecho individual.

Los personajes principales revisten así un carácter ejemplar y su sufrimiento y su fracaso serán el sufrimiento y el fracaso de la sociedad a la que pertenecen. Sin la salvación del protagonista, nada resta por hacer: el mundo que lo ha condenado sucumbirá al ejecutar el castigo que le ha impuesto, lo que sacado de su contexto literario supondría que mientras hubiera esclavitud en Cuba, toda la isla sería esclava.

Para esta novelística, el héroe protagonista es ante todo un ser social doblegado a los condicionantes que le impone la realidad. Para padecer esta servidumbre no es necesario que el personaje en cuestión sea esclavo, ni que prevalezca el color negro en su piel. Ese es el caso, por ejemplo, de Cecilia Valdés, la protagonista femenina de la novela homónima de Villaverde, un personaje que responde al canon clásico de la belleza de raza blanca, aunque ciertos rasgos delatan su origen negro; un fenómeno similar es el del rancheador Valentín Páez, del cuento de Morillas, campesino libre,

10 Pérez de Zambrana, Luisa, «Carta a don Anselmo Suárez y Romero», en Los Zambrana, ed. Maellen Zambrana (La Habana: Imprenta Fernández y Cía., 1952), V, p. 68. 
blanco, que se convierte en cazador de negros cimarrones por una venganza personal. Bajo cada uno de los personajes de las novelas mencionadas subyace una problemática diferente -amorosa, económica o una privación de libertad-, pero todos deben esa concreta circunstancia vital al hecho de vivir en una sociedad esclavista.

Por esta razón, puede establecerse el metagénero novela antiesclavista cubana con el siguiente lema: «texto literario cuya dinámica textual expresa la progresión de uno o varios personajes sometidos al dictado de la esclavitud en la Cuba colonial preabolicionista».

Existen otros relatos que presentan características comunes, pero que no incluimos en este corpus literario por haber sido redactados en fecha posterior a la abolición de la esclavitud (1880/1886), como Romualdo, uno de tantos (1881/1891) de Francisco Calcagno o Sofía (1891) y La familia Unzuazu (1901) de Martín Morua Delgado ${ }^{11}$. También se encontraría al margen la novela de José Ramón Betancourt Una Feria de la Caridad de 18... (1858), en la cual el soporte estructurante de la acción no es la esclavitud, sino el juego, pese a contener unas de las páginas más decididamente abolicionistas de la literatura cubana, que al parecer fueron intercaladas en la versión definitiva de Barcelona en $1885^{12}$.

No podríamos llamar a estas novelas «proabolicionistas»; bajo nuestra óptica la abolición supone el paso definitivo contra la pervivencia de la esclavitud, y en la época en que se compusieron la mayoría de estos relatos ésa era una aspiración casi ilusoria, incluso para los más avanzados políticamente. Ni siquiera los textos más próximos a la Ley de Patronato de 1880 modificaron por completo el tono moderado de sus antecesores. En general, sí manifestaron una abierta repulsa contra el sistema de la esclavitud en Cuba; en esta condena tenía cabida tanto la solidaridad humanitarista en favor del esclavo oprimido, como el hecho de reconocer las consecuencias funestas de la esclavitud para la misma sociedad blanca que la potenciaba.

«Antiesclavista» es por tanto un término más acorde con la temática de estas novelas, ya que se escriben como rechazo a la esclavitud. Tampoco es oportuno el título de «novela antitratista» que emplean algunos críticos, por encerrar un cierto menosprecio hacia estos escritores; «antitratista» sería el relato que se declara en desacuerdo con el comercio negrero, escrito con una única finalidad: acabar con la trata en cumplimiento de los pactos hispanobritánicos de 1817 y 1835 . Incluso la novela antitratista expresaría una hostilidad frente al negro: Cuba debía ser blanca, no mulata;

11 Aunque Cecilia Valdés fue publicada en 1882, Cirilo Villaverde la dio por terminada en 1879. Problemas de espacio nos obligan a excluir esos otros relatos cubanos en los que persistía una oposición similar al régimen discriminatorio de su país, porque, aunque la esclavitud había sido abolida, el negro soportaba el mismo papel que sus ascendientes esclavos. Tampoco se nombran dos textos de un valor testimonial incuestionable: Diario del Rancheador y Biografía de un cimarrón, recogidos por Cirilo Villaverde y Miguel Barnet, respectivamente; son documentos de gran verismo, en una línea próxima a la Autobiografía de Manzano, pero alejados de los propósitos de este ensayo.

12 Vid. González de Cascorro, Raúl, «Prólogo», en Betancourt, José R., Una feria de la Caridad de 18... (La Habana: Letras Cubanas, 1978), pp. 7-8. 
como las leyes prohibían la mezcla de razas ${ }^{13}$, el final de la trata, aunque no del régimen de vida esclavo, conduciría a una extinción gradual de la esclavitud y, con ella, de la raza negra en la isla.

Así planteado, el autor de novelas antitratistas ha podido ser calificado de racista, por ejemplo, por Josefa Hernández Azaret: «Dentro de esta narrativa, se convirtió el negro en una figura importantísima de novelas y relatos, pero el racismo, del que no pudieron escapar los escritores y sus intereses clasistas, tergiversó, en una mayor o menor medida, la imagen del esclavo y su condición humana. De Francisco a Cecilia Valdés (en su última versión) las novelas más representativas que tocan el tema de la esclavitud no se atrevieron a plasmar en toda su dimensión la capacidad del negro, su inteligencia y la importancia de su lucha emancipadora contra el blanco dominante» ${ }^{14}$.

No debieron ser de esta opinión las autoridades isleñas, como lo demuestran la negativa a permitir la difusión de Sab en Cuba y a la publicación de unos «Fragmentos» de Francisco. Curiosamente, Hernández Azaret sólo salva de su crítica a El Ranchador porque en ella descubre la «esencia de la cimarronería», único de estos relatos antiesclavistas que fue publicado en Cuba mientras persistía la esclavitud.

Luis Yero Pérez comparte el enfoque de Azaret; la literatura, dice, «al tratar el tema de la esclavitud recogía las inquietudes más progresistas del momento; pero, al mismo tiempo, registraba las concepciones discriminatorias de la moral esclavista./.../ Ninguno de los escritores que trató el tema de la esclavitud pudo escapar de los prejuicios raciales» $»^{15}$. Había que «limpiar» la isla de negros para preservar la raza blanca y todo su poderío social. Más atinado resulta Yero Pérez cuando señala el carácter independentista de esta literatura: al fustigar la esclavitud, «no sólo criticó el tráfico negrero sino, incluso, los efectos malsanos que generaba la esclavitud en tanto que institución coercitiva a favor de los intereses españoles. Era un modo indirecto de iniciar la descolonización gradual de la isla» ${ }^{16}$.

\section{Escritores e ideas}

Si teóricamente englobáramos a estos siete autores en una familia común a todos ellos, intentaríamos ver hasta qué punto esta hipótesis responde a un presupuesto básico en sociología de la literatura: la existencia de un sujeto colectivo en toda

${ }^{13} \mathrm{La}$ temática de las relaciones sexuales interraciales ha sido ampliamente tratada por Verena Martínez Alier. Vid. Martínez Alier, Verena, Marriage, class and colour in the Nineteenth Century in Cuba (Nueva York: Cambridge Press, 1974).

${ }^{14}$ Hernández Azaret, Josefa, «Pedro José Morillas dentro de la narrativa antitratista del siglo XIX. Tratamiento del negro», Santiago, n. 41 (marz. 1981), p. 175.

15 Yero Pérez, Luis, op., cit., pp. 72-72. Por esta misma causa, investigadores como José Antonio Portuondo observan en la literatura un medio de afirmar el control económico, social e incluso político, de la alta clase criolla.

${ }^{16}$ Ibidem, p. 72. 
estructura y obra literaria. Este dato no anularía al autor individual, como suele discutirse en términos sociológicos; antes al contrario: hermana el concepto de autoría con el de creación colectiva. Juan Ignacio Ferreras ha examinado esta problemática y ofrece un enfoque particularmente adecuado para el estudio de los autores de novelas antiesclavistas.

Ferreras comienza por aclarar que el sujeto individual, o autor, «no es el representante del sujeto colectivo, ni su portavoz: está inmerso en el sujeto colectivo, por él mediado, pero posee su propia autonomía que conviene esclarecer. Las relaciones del sujeto colectivo con respecto al sujeto individual, o autor, son mediaciones explicativas» ${ }^{17}$. En su crítica distingue entre una conciencia colectiva generalizada, una conciencia colectiva particularizada y una conciencia individual.

La primera existe en la sociedad, pero no por ello está materializada artísticamente. Podríamos indentificarla con la superestructura marxista, definida por Julio Rodríguez-Puértolas como «el conjunto de ideas e instituciones de un momento histórico dado, conjunto originado como consecuencia de unas ciertas relaciones de producción o base» ${ }^{18}$. La conciencia particular sí es la materialización y conceptualización de esta conciencia general por parte de un grupo. Y la conciencia individual, lógicamente, pertenece al pensamiento del autor, ya sea para rebelarse ante esa conciencia colectiva particularizada o para afirmarla.

Estos tres niveles no son compartimentos estancos, pues, como todo elemento válido por su procedencia social, evoluciona al ritmo marcado por las coordenadas espacio-temporales en que se produzca. La novela antiesclavista cubana se origina en un momento álgido de la historia de la colonia y concluye cuando este soporte socioeconómico hace crisis. Este proceso se limita en este caso al período comprendido entre 1838 y 1882, años que corresponden al nacimiento de los primeros relatos antiesclavistas y a la publicación de la última novela del género, Cecilia Valdés; la relación que este fenómeno sostiene con el devenir histórico cubano es lo que ahora intentamos analizar.

Si aplicamos los términos de Ferreras, la conciencia colectiva generalizada correspondería al pensamiento determinado por la mayoría blanca de la isla; esta conciencia refleja los esquemas esclavistas de la sociedad cubana, junto a un paradójico anticolonialismo debido a su proyección como entidad económica independiente en el mercado internaciona ${ }^{19}$. El grupo liderado por Domingo del Monte se habría desarrollado como conciencia colectiva particularizada al cuestionar los plantea-

${ }^{17}$ Ferreras, Juan I., Fundamentos de sociología de la literatura (Madrid: Cátedra, 1980), p. 50.

${ }^{18}$ Rodríguez-Puértolas, Julio, «La crítica literaria marxista», en Introducción a la crítica literaria actual (Madrid: Playor, 1983), p. 210.

${ }^{19}$ Cuba en el siglo XIX presenta características especiales que dificultan la comprensión de la auténtica naturaleza de su desarrollo histórico. Su estructura económica se apoyaba en un principio de producción esclavista, contrario, como ha demostrado la historia, al librecambismo; sin embargo, su estrategia de mercado seguía una línea pseudoliberal que convertiría a Cuba en la potencia comercial del Caribe. Mientras tanto, de forma paradójica, su política se encontraba «secuestrada» por los intereses de la metropoli. 
mientos rectores de la sociedad en que vivían. Y a su vez, en esta dinámica se articularía la conciencia individual de los miembros del grupo.

Con respecto a las dos últimas, su análisis sólo adquiere pleno sentido, desde la perspectiva literaria en que nos encontramos, cuando se concretizan en una forma textual, llámese obra de texto, poema o narración; en definitiva, sólo será objeto de estudio el momento en que esa conciencia se filtra en los relatos antiesclavistas que se han seleccionado aquí.

Tradicionalmente la crítica ha estudiado cómo cada una de esas conciencias se hace portadora de una determinada ideología, concepto polémico en teoría literaria. France Vernier propone considerar la ideología como un «instrumento de acción al servicio de una clase $»^{20}$. Pero siempre de una forma no estática ni estructural.

Vernier examina detalladamente lo que llama ideología dominante, un impacto común a las relaciones imaginarias del mundo, que obedece a los intereses de la clase social en el poder hasta constituir esos intereses en «valores universales -morales, espirituales, estéticos- y justificarlos; la ideología dominante deberá absorber los elementos extraños a la ideología que amenazan constantemente con conmover su sistema ficticio ${ }^{21}$, y unificar sus contradicciones internas para consolidarse frente a oposiciones externas.

En este sentido, la ideología de la burguesía esclavista cubana seguiría las directrices marcadas por Vernier para la clase en el poder. Su cohesión interna hizo prosperar su dilatado ciclo, si bien cuando más dificultades hallaba en su contra -la presión abolicionista británica y las tiranías de los capitanes generales, sobre todo Vives y Tacón-, un sector minoritario de la población levantaba su voz para interrogar a los cubanos sobre la validez del sistema que ellos mismos habían apoyado.

Se produjo entonces el choque entre dos ideologías, enfrentadas dialécticamente: los patricios enriquecidos con el comercio de café, de azúcar y de negros veían comprometidos sus intereses por las tesis antiesclavistas del grupo delmontino; utilizaron todos los elementos que la infraestructura de la isla había puesto a su servicio -la censura, especialmente- para solucionar este divorcio nacido en el seno de su sociedad y que terminaría con la victoria del régimen gobernante.

Históricamente sabemos que la Conspiración de la Escalera (1844) apartó durante años al intelectual de la lucha política. Sin embargo, la derrota moral que infringió en los hombres de letras no fue absoluta, como lo confirman las dos últimas novelas de sentido antiesclavista, El negro Francisco (1873) y Cecilia Valdés (1882). En última instancia, los delmontinos fueron los precursores de la batalla contra el régimen de esclavos y, si una vez el sistema impidió su desarrollo, al cabo, el transcurso de los hechos les daría la razón, y toda Cuba se alzaría frente al colonialismo y la esclavitud.

La trascendencia de las tesis de Domingo del Monte, su impronta en la composición de los primeros alegatos literarios de orientación antiesclavista, Francisco y la Autobiografía de Manzano, y la postura de los integrantes de su tertulia merece una

${ }^{20}$ Vernier, France, ¿Existe una ciencia de lo literario? (Madrid: Akal, 1975), p. 26.

${ }^{21}$ Ibidem, p. 27. 
atención mayor. Cabría preguntarse por qué se alude habitualmente a la existencia del círculo delmontino como detonante de esta literatura. Por ejemplo, Luis Yero Pérez afirma que «del seno de la tertulia delmontina saldría una literatura de denuncia contra los mecanismos coloniales» ${ }^{22}$.

El método estructuralista-genético de Lucien Goldmann podría proporcionar la respuesta adecuada. Su hipótesis fundamental predica el carácter colectivo de la creación literaria», la cual a su vez proviene del hecho de que «las estructuras del universo de la obra son homólogas a las estructuras mentales de ciertos grupos sociales o en relación inteligible con ellos, mientras que en el plano de los contenidos, es decir, de la creación de mundos imaginarios regidos por estas estructuras, el escritor tiene una libertad total» ${ }^{23}$. La relación que se establece entre el grupo creador y la obra se presenta según el siguiente modelo: el grupo genera en la conciencia de sus componentes unas tendencias afectivas e intelectuales -visiones del mundo- que intentan ofrecer una solución coherente a la problemática planteada.

Según Goldmann, esta teoría descubre un enfoque diferente a la sociología, que ya no busca en la obra el reflejo exacto de unas ideas, sino la constitución de esas creencias en elementos integrantes de la estructura de la obra literaria. De ser una sociología de los contenidos, generalmente marginada por la crítica que pregona el análisis inmanente de los textos, la sociología se suma también a la corriente estructuralista y proclama la alianza de estos dos sistemas para enriquecer el estudio de la obra literaria.

Si agrupáramos la metodología expuesta hasta ahora, podríamos presentar este modelo para la narración antiesclavista cubana:

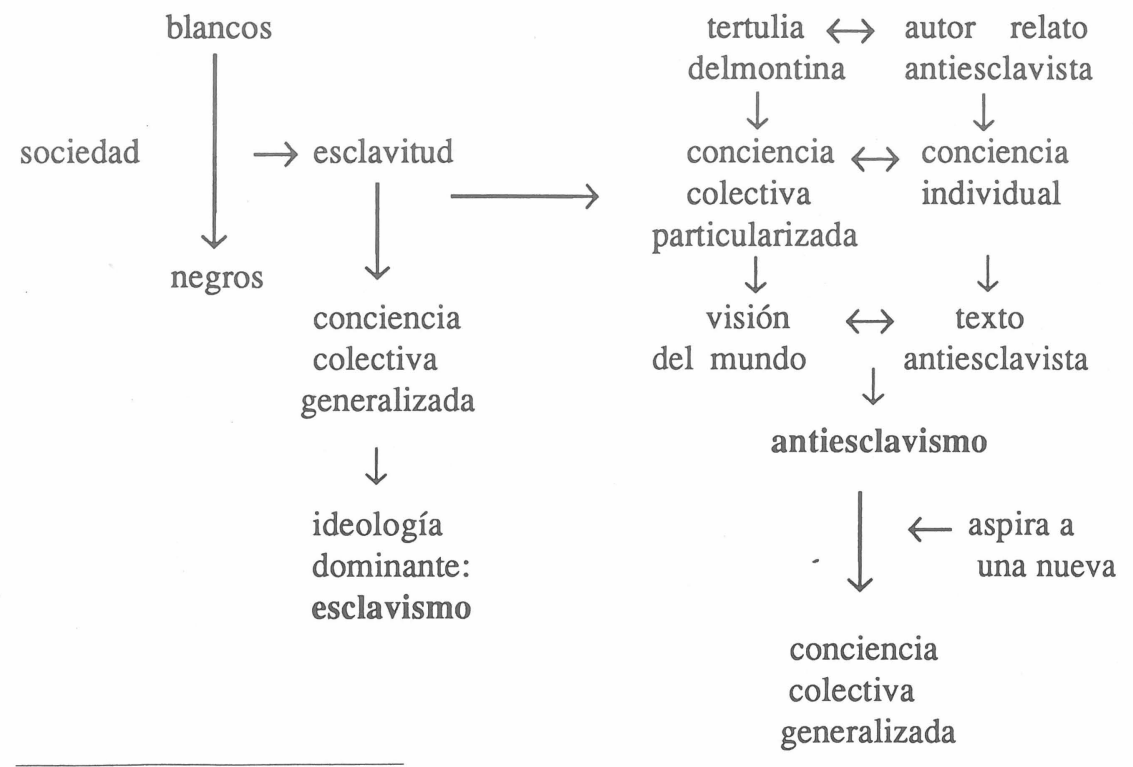

22 Yero Pérez, Luis, op., cit., p. 69.

${ }^{23}$ Goldmann, Lucien, Para una sociología de la novela (Madrid: Ayuso, 1975), p. 226. 
En su carácter opositor a la ideología dominante, Félix Tanco fue, sin duda, uno de los amigos de Del Monte que más tenazmente se definió contra el sistema esclavista. Más que en Petrona y Rosalía su pensamiento se halla expuesto en las cartas que envió a Del Monte y que este agrupó con toda intención en un tomo independiente de su Centón Espistolario, porque, como ha visto Salvador Bueno, «están llenas de observaciones violentas y drásticas opiniones, de desplantes y formas de expresión procaces que chocaban con el gusto de la época» ${ }^{24}$.

A raíz de la lectura de Bug-Jargal (1826) de Víctor Hugo, Tanco estimó que el verdadero objeto de la literatura cubana residía en el mestizaje entre negros y blancos:

«Los negros en la isla de Cuba son nuestra poesía, y no hay que pensar en otra cosa, pero no los negros solos, sino los negros con los blancos, todos revueltos, y formar luego los cuadros, las escenas, que a la fuerza han de ser infernales y diabólicas, pero ciertas y evidentes ${ }^{25}$.

El tiempo vendría a dar la razón a Félix Tanco; no cabe duda de que la mulatez se convertiría en seña de identidad para Cuba, pero en esta época era un atrevimiento el sugerirlo siquiera, aunque la realidad en sí se encargaba de derrumbar estos prejuicios. Desde los siglos del descubrimiento el hombre blanco se había unido a mujeres indígenas, que fueron sustituidas por negras africanas a medida que la raza india disminuía. El motivo lo explica Elías Entralgo en su artículo sobre la mulatización cubana: «Característica peculiar de la conquista española de América fue la de haberse realizado con la única presencia del hombre, y por ello, con exclusión de la mujer. De ahí que desde los tiempos más remotos se iniciara en estas sociedades una amalgama de razas» ${ }^{26}$. En Cuba, además, a esa primera necesidad instintiva se añadiría progresivamente una leyenda sobre la voluptuosidad de la mulata, que será captada de un modo magistral por toda la literatura antiesclavista.

Sin embargo, no producía el mismo efecto convivir a diario con el mulato -con lo cual, la «buena sociedad» terminaba por ignorarlo-, que comprobar lo miserable de su forma de vida en un texto literario. Por esta causa, la unión de las dos razas no debía ser el único tema de las ficciones; Tanco alude a escenas «infernales y diabólicas» y había para ello una razón de peso: la esclavitud había convertido a los hombres en bestias de carga, sin un alma y sin un cuerpo del que disponer porque no le quedaban fuerzas para satisfacer sus necesidades físicas o espirituales, y en la mayoría de los casos no disfrutaban de tiempo libre para el descanso o la diversión.

El cuerpo del esclavo era vejado constantemente, porque no le pertenecía: su único dueño era el amo, que podía castigarlo brutalmente hasta conducirlo a la muerte si lo deseaba. El primer cuadro de Francisco entra de lleno en ese universo degradado; el mayoral azota a un negro, el esclavo protagonista de la novela, por mandato del amo:

${ }^{24}$ Bueno, Salvador, «La primitiva narración antiesclavista cubana», Universidad de La Habana, n. 207 (ene.-marz. 1978), p. 150.

${ }^{25}$ Del Monte, Domingo, op., cit., VII, p. 132.

${ }^{26}$ Entralgo, Elías, «La mulatización cubana», Casa de las Américas, n. 36-37, (may-. ago. 1966), p. 76. 
«-Todavía no me ha respondido usted. ¿Le chorreó la sangre? ¿Se puede menear? ¿Le arrancó usted la tira del pellejo? -¿No le estoy contanto al niño? Les mandé a Juan, a Wenceslao y a Crispín que me lo sujetaran por las manos y las patas; y yo mismo, con estas manos - ¡cómo las maldecirá el maldito!- empecé a desflecarlo. «Uno, dos..., lleva la cuenta», le dije, «en equivocándote, vuelvo a empezar la fiesta». A las ocho se equivocó y tuve que cumplirle la palabra. ¿Qué iba a hacer? Pero el negrito se emperró, que parecía un becerro montuno y no quiso contar más; mordía la tierra, se mordía los bembos, echaba sangre por la boca y crujía los dientes. Bien. La jarana le costó treinta zurriagazos de añadidura. Por cincuenta llevó ochenta» (Francisco, pp. 43-44).

El problema no afectaba solamente a los esclavos; en la práctica del sistema esclavista se había llegado a la transposición de sus esquemas y vicios a la sociedad blanca, con el consentimiento cómplice de las autoridades. Relataba Tanco este suceso a Del Monte:

«Vaya una noticia importante: El jueves de la semana pasada se le ha pegado a un muchacho de 13614 años de edad en el colegio que dirige don Pedro Saavedra, natural de las Islas Canarias, un bocabajo con todas las formalidades de estilo lo mismo que se pega a un negro. Fue el verdugo el mismo Saavedra: el muchacho está en cama, reconocido por los médicos que le pusieron sanguijuelas y ventosas en la espalda y asentaderas ${ }^{27}$.

Los delmontinos pensaban que una descripción descarnada de los hechos ayudaría a combatir los abusos de los blancos. Es conveniente subrayar la ausencia de ataques directos a la esclavitud en los primeros relatos; las censuras a este régimen amoral deberían formularse de manera implícita, por consejo de Del Monte. Aunque firma la carta José Zacarías González del Valle, su autor sólo traduce las advertencias que el maestro hiciera a Suárez y Romero:

«Así que Domingo te indicó que suprimieras lo subversivo, no porque, maleando sus buenos principios, lo crea perjudicial, sino porque vio que el novelista no debe poner arengas en boca de sus personajes, y menos siendo inverosímiles; que la moralidad o la máxima política que domine en tu obra se desprenda como de suyo, sin apuntarla, ni pregonarla a cada paso, y que por lo mismo que una novela tuya sirve para ir corrigiendo nuestras costumbres, ha de salir verdadera, cubana y provista de hechos indisputables que no haya más que ver el retrato y abominar$10{ }^{28}$.

Su pretensión más inmediata era la de moderar los excesos del sistema esclavista, como se desprende de esta célebre frase de Tanco elevada a contraseña del antiesclavismo: «Un bocabajo menos que se dé, o un negro menos que se mate por

${ }^{27}$ Del Monte, Domingo, op., cit., VII, p. 132.

${ }^{28}$ González del Valle, José Z., La vida literaria en Cuba (1836/1840) (La Habana: Publicaciones de la Secretaría de Educación, 1938), pp. 93-94. 
nuestra influencia, será para nosotros mejor galardón mill veces que todos los honores literarios del mundo» ${ }^{29}$. Quizás nunca llegaron a plantearse la posibilidad de erradicar el sistema -exigencia que suele hacer la crítica actual-, pero, al menos, deseaban humanizarlo, si es que alguna esclavitud puede llamarse humana. No se debe minimizar este deseo que bastó para enemistarlos con la minoría gobernante y con la aristocracia de la tierra y el comercio, clases a las que intentaron avergonzar mediante sus relatos, y que impidieron que estos fueran publicados; Suárez y Romero defiende la legitimidad de Francisco para modificar el régimen opresivo de su tierra:

«En cuanto al fin de la obra, no le cabrá duda en cuál sea aliviar la suerte desgraciada de los negros, sacando a la cara de los blancos los colores de la vergüenza, porque en pos de ésta viene el arrepentimiento, y luego la enmienda iquién pudiera conseguir un objeto tan grandioso! iQué gloria para mí! Yo he vivido en ingenios desde chico, y después que los he mirado con ojos más claros, casi se me han saltado las lágrimas al ver tanto extravío, tanto de inhumanidad y de fiereza. Por eso es menester pintarlos, pintar a los mayorales, a los mayordomos, a los médicos, a todos sus operarios, a los mismos dueños, que poco les aventajan en este particular» ${ }^{30}$.

El ideario antiesclavista es un factor destacado de los textos señalados, especialmente de Sab, El negro Francisco y Cecilia Valdés, obras compuestas al margen de las máximas delmontinas, por lo que no evitaron lo «subversivo». Gertrudis Gómez de Avellaneda hace hablar así al mulato Sab en la novela de idéntico nombre:

«No tengo tampoco una patria que defender, porque los esclavos no tienen patria; no tengo deberes que cumplir, porque los deberes del esclavo son los deberes de la bestia de carga, que anda mientras puede y se echa en tierra cuando ya no puede más. $\mathrm{Si}$ al menos los hombres blancos, que desechan de sus sociedades al que nació teñida la piel de un color diferente, le dejasen tranquilo en sus bosques, allí tendría patria, amores..., porque amaría a una mujer de su color, salvaje como él, y que como él no hubiera visto jamás otros climas ni otros hombres, ni conocido la ambición, ni admirado los talentos. Pero jah!, al negro se le rehusa lo que es concedido a las bestias feroces, a quienes le igualan; porque a ellas se les deja vivir entre los montes donde nacieron y al negro se le arranca de los suyos» (Sab, p. 232).

Se aprecia una clara oposición sociedad/naturaleza, junto a una defensa de los valores del negro como ser humano -se reconoce su capacidad de amar y pensar, por lo que se agrava todavía más la animalización de que es víctima-, y sobre todo destaca un canto a la vida salvaje, muy en la línea del credo romántico de la Avellaneda, formado en los versos de Heredia y en las narraciones indígenas de Saint-Pierre y Chateaubriand. La crítica a la sociedad se realiza desde el punto de vista del oprimido, que asemeja su condición a la del animal, menos envilecido aún que él por cuanto se

${ }^{29}$ Del Monte, Domingo, op. cit., VII, p. 118.

${ }^{30}$ Suárez y Romero, Anselmo, «Dos cartas a José Jacinto Milanés (1838)», Revista de la Biblioteca Nacional José Martí, n. 1 (ene.-marz. 1954), p. 54. 
respeta su libertad. Asoma, pues, en estas palabras el mito del buen salvaje, aunque en la literatura cubana el negro ha suplantado el papel tradicional del indio.

En El negro Francisco de Zambrana se adopta un enfoque similar, sólo que esta vez es el autor mismo quien expresa su opinión por boca del narrador; con el estilo descarnado que caracteriza estas narraciones, Zambrana aborda uno de las facetas más controvertidas de este régimen, la trata. Solo Cecilia Valdés se atreverá a plantearlo $\tan$ abiertamente:

«Ha habido quien ha escrito que la esclavitud no es una desgracia para el negro. Un periódico español, que calificaba de frases huecas los lamentos de los abolicionistas, se tomó el trabajo de averiguar el origen de la trata, y se creyó victorioso /.../ cuando supo que el rey salvaje de Dahomey vendía a los blancos los prisioneros de guerra que estaban destinados al sacrificio. La esclavitud venía a ser una especie de redención. El negro, que habría debido expirar bajo la cuchilla del victimario allá en el fondo de su agreste país, en la sombra de la barbarie era atado como un lío, /.../ hundido en la bodega de un estrecho barco, transportado, no como se transporta a un hombre, sino como se transporta a una mercancía /.../; si tenía bastante energía vital, no moría de hambre, ni de sed, ni de asfixia durante el trayecto, llegado a Cuba podía en cambio morir de insolación, en la árida playa, mientras se aguardaban los compradores /.../; luego vivían sin patria, sin dignidad, sin reposo, sin esperanza y solían matarlo a latigazos. Todo esto cuando se le había iluminado lo suficiente para que lo comprendiese bien» (El negro Francisco, p. 252).

Mediante un lapso en la línea argumental se introduce esta larga reflexión que contempla, no sin cierta ironía, el mecanismo completo de la esclavitud. Primero, su justificación por razones humanitarias -la esclavitud salva a los negros de la barbarie de su especie para encontrar una vida abyecta en el mundo civilizado, donde el sacrificio se transformaba en violación de todos sus derechos-. En el intermedio, la travesía desde Africa, amontonado en el vientre de los barcos negreros, subalimentado y sujeto a unas inexistentes condiciones higiénicas durante meses. Antonio de las Barras y Prado, historiador de la ciudad de La Habana, ofrece este patético cuadro del transporte negrero:

«Los sexos vienen mezclados a bordo en completo estado de desnudez, lo mismo que si se tratara de un montón de animales, ajenos a todos sentimiento racional, e incluso al del más elemental aseo, llenándose de inmundicias, por cuya causa, para evitar que se infeccione el aire del buque, tienen los tripulantes que baldear a los negros dos o tres veces al día arrojando sobre ellos gran número de cubos de agua de $\operatorname{mar} \aleph^{31}$.

No menos increíble es la visión que Isabel Ilincheta -oponente femenina de la protagonista de Cecilia Valdés- tiene en el ingenio que va a heredar su prometido Leonardo, «La Tinaja», todo un orgullo para la familia Gamboa y un infierno despre-

${ }^{31}$ Barras y Prado, Antonio de las, La Habana a mediados del siglo XIX. Memorias (La Habana: Imprenta de la Ciudad Lineal, 1926), pp. 137-138. 
ciable para el talante delicado y piadoso de Isabel, que siempre había procurado dulcificar la servidumbre de los esclavos que le pertenecían:

«En las pocas horas de su estancia en el ingenio, había podido observar cosas que, aunque oídas antes, no las creyó nunca reales ni verdaderas. Vio, con sus ojos, que allí reinaba un estado permanente de guerra, guerra sangrienta, cruel, implacable del negro contra el blanco, del amo contra el esclavo. Vio que se aplicaban castigos injustos y atroces por toda cosa y a todas horas; /.../ que el trato era inicuo, sin motivo que le aplacara, ni freno que le moderase; que apelaba el esclavo a la fuga o al suicidio en horca como el único medio para liberarse de un mal que no tenía cura ni intermitencia.

/.../ Pero nada de esto era lo peor; lo peor, en opinión de Isabel, era la extraña apatía, la inhumana indiferencia con que los amos miraban todos los sufrimientos, las enfermedades y aún la muerte de los esclavos. Como si a nadie le importara su vida bajo ningún concepto. Como si no fuera nunca el propósito de los amos corregir y reformar a los esclavos, sino meramente el deseo de satisfacer una venganza. Como si el negro fuese malvado por negro y no por esclavo. Como si tratado como bestia se extrañaba que se portase a veces como una fiera» (Cecilia Valdés, pp. 292-3).

Resuenan aquí la queja de $S a b$, la protesta de Tanco o la absurda injusticia de Francisco. Isabel Ilincheta observa perpleja la paradoja de un sistema descabellado, que se anuncia como redentor del espíritu salvaje del negro, a quien, en teoría, debe adoctrinar y «civilizar» y que, en verdad, sólo persigue explotarlo. Los «como si» del monólogo del personaje descubren el rostro auténtico de la realidad esclavista, porque a nadie importaba la vida del esclavo mientras resultara fácil sustituirlo, no existían propósitos altruístas en la práctica del régimen que había llevado a olvidar la convivencia pacífica de los seres humanos para contentar los más bajos instintos de unos y otros: el blanco odiaba al negro porque era diferente, y para el negro, africano o criollo, libre o esclavo, el rencor era el único sentimiento que no se le había prohibido.

La lectura de los textos que se han citado ofrece datos suficientes para comprender que significó la esclavitud para esta generación de escritores. Aunque no todos los relatos ofrecen una perspectiva unitaria, no cabe duda de que la consigna común a todos ellos partía de su rechazo a la situación extrema de su país en las décadas previas a la Ley de Abolición y a la Independencia. Su sentido, como se indicó, suscita dudas en la crítica contemporánea, tanto como la ausencia de un espíritu verdaderamente revolucionario o la ideología «blanca» presente en las novelas.

Sin embargo, este tipo de literatura era el único que podía sobrevivir en la Cuba colonial. La razón, como advierte William Luis, es muy simple: «el grupo, o concepto, antiesclavista como movimiento literario -político o económico- solamente podía existir como movimiento blanco. El lenguaje, y la escritura, como medio de expresión de la burguesía, solamente existe desde la dominante estética blanca. De una manera muy obvia, las novelas describen una situación poco familiar, desde una visión 
externa. Lo que es inequívoco es que el otro punto de vista no era posible, por lo menos durante el siglo $\mathrm{XIX} »^{32}$.

Y siempre que nacía un escritor entre las filas de los marginados, debía asumir las reglas de la literatura dominante. Tal fue el caso de Juan Francisco Manzano; su «progreso» social exigía que aceptase los modelos: «el esclavo tenía que abandonar su marco referencial de negro y aceptar otro completamente distinto. Psicológicamente tenía que suprimir su ser y convertirse en otra persona para poder escribir sobre su condición desde la estética blanca, la única estética» ${ }^{33}$.

Estética blanca que hizo del negro el objeto de su lienzo. A él le unían relaciones económicas y sociales, y al mismo tiempo se sentía atraído por ese ser que disfrazaba bajo el color de su piel una forma de vida diferente. Los primeros narradores cubanos desnudaron esa personalidad y con su literatura contribuyeron a dar a conocer esos códigos que la mayoría de la población intentaba anular. El mosaico de razas quedó perfectamente dibujado con el material de estos novelistas, y la historia de Cuba se tradujo en tema de ficción; podemos decir, con Salvador Bueno, que la literatura «le sirve de espejo: conforma un método de conocimiento de nuestra existencia nacional» ${ }^{34}$. Máxime cuando el tema del negro en las letras de Cuba conforma una novelística que, además, es la primera de su historia literaria.

${ }^{32}$ Luis, William, «La novela antiesclavista: texto, contexto y escritura», Cuadernos Americanos, n. 3 (may.-jun. 1981), p. 114.

${ }^{33}$ Ibidem, p. 114.

${ }^{34}$ Bueno, Salvador, «Los temas de la novela cubana», Asomante, n. IV, (oct.-dic. 1960), p. 39. 